\title{
Review of Faculty-Librarian Collaborations:
}

\section{Integrating the Information Literacy Framework into Disciplinary Courses}

\author{
Cathy Troupos \\ Wheaton College
}

\begin{abstract}
Review of Faculty-librarian collaborations: Integrating the Information Literacy Framework
into disciplinary courses. Edited by Stöpel, M., Piotto, L., Goodman, X., and Godbey, S. (Chicago, IL: Association of College and Research Libraries 2020. 238pp.
\end{abstract}

Keywords: ACRL Framework, faculty-librarian collaboration, information literacy, instruction

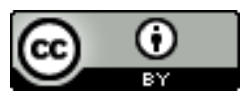

This is an Open Access article distributed under the terms of the Creative Commons Attribution 4.0 International License (http://creativecommons.org/licenses/by/4.0), which permits unrestricted use, distribution, and reproduction in any medium, provided the original work is properly cited. 
When drafting the ACRL framework, the developers noted that emphasis on metaliteracy rather than skills-based outcomes creates more space for teaching librarians and faculty to collaborate to help students. In short, the framework opens "the way for librarians, faculty, and other institutional partners to redesign instruction sessions, assignments, courses, and even curricula" ("Framework"). In reality, it can be challenging and time-consuming to develop such partnerships, yet when those relationships do emerge, the outcomes lead to mutual satisfaction for librarians and faculty and greater success for students. Faculty-librarian collaborations: Integrating the Information Literacy Framework into disciplinary courses presents many such successful partnerships between teaching faculty and librarians at AMICAL institutions along with a framework for how to create such opportunities.

The foundation for the book was a two-day workshop for librarians and teaching faculty partners hosted by AMICAL, entitled Co-Designing: Integrating Information Literacy into Your Disciplinary Course (p. 10). Understanding that the "the successful integration of information literacy into the curriculum requires collaboration between librarians and disciplinary faculty” (p. 10), workshop designers used backward design and active-learning techniques to challenge partners to rework course learning objectives, assignments, and assessment strategies to embed ACRL frames within the course design. The targeted courses spanned the disciplines and included all levels of higher education from first-year undergraduates to first-year graduate students.

The introduction explains the context for the workshop and subsequent case studies. AMICAL is an international cohort of liberal-arts colleges that follow an American-based educational model. AMICAL seeks to "advance learning, teaching and research through the collaborative development of library and information services and curricular resources at member institutions" (p. 1). InformationJournal of New Librarianship, 6 (2021) pp. 70-75 10.21173/newlibs/10/8 
literacy programs at these institutions range from developing to well-established. While the case studies described were situated at institutions in Europe, Africa, and the Middle East, and the cultural contexts did affect the approaches and outcomes, most instruction librarians will find the examples relevant to their own contexts.

The remainder of the book is organized into three sections: Chapters (which offers a background of the project), Case Studies, and Lesson Plans. In the first section, two chapters describe the workshop and the related assessment of the workshop and the pilot courses. Chapter one details the prework for and the activities that took place at the workshop. Beginning with a shared reading of the framework and an article discussing disciplinary core concepts (p. 11), the teaching faculty and the librarians developed a deeper understanding of the skills, knowledge, and expertise of their partners. After arriving at the workshop and discussing the ACRL framework in relation to their targeted disciplines, the groups developed learning outcomes that incorporated the frames into their courses. The partners then created activities and instruction plans to support the outcomes. Upon returning to their home institutions, the work continued through the piloting of the revamped courses. Chapter two details the assessment which sought to evaluate "whether the courses had been successful with regard to both learning and teaching and to determine the new fruits the co-designing had produced" (p. 22). Though some negative themes emerged, the outcomes were overall positive with displays of increased student learning and newly formed appreciation between librarians and faculty.

Through detailed descriptions of the scheduling, learning prompts, activities, and assessment tools, these initial chapters could serve as a foundation for those interested in forming their own development opportunities for librarians and faculty. While a full two-day event may be out-of-reach for most, ideas from the workshop could be adapted to a smaller scale with a similar goal of helping 
"both parties to learn from each other and reach a common language" (p. 124). Indeed, reading about such collaborations between faculty and librarians is inspiring, and the subsequent assessment demonstrated that these efforts were not in vain.

The next section, Case Studies, is the heart of the book. Each chapter describes contextual information, such as descriptions of the courses and revised learning outcomes, activities, and assessment measures, with some including subsequent revisions based on their initial experiences (notably Case Study 7). Although each case study defines a unique experience, a few key themes surface. First, the writers confirm the new understandings that develop when working together; teaching faculty gain an appreciation for the expertise of librarians; librarians gain a better understanding of the classroom culture, content, and challenges. In sum, partnerships emerged that were "built on equity and co-teaching principles" (p. 124). While it is true that these collaborations brought newfound respect, they also demand considerable time and effort. Aside from the time spent at the workshop revamping outcomes and activities, each case study also included multiple instructions sessions with the librarian, with many including at least three sessions. On the one hand, as they added more sessions, participants discovered that significant learning occurs when instruction is placed at the point-of-need. Multiple sessions allowed "more time for explaining activities, providing more examples, and giving students more time to practice” (p. 66). On the other, some writers questioned whether such a model is sustainable or scalable when current library staff may already be "overwhelmed with current tasks, which makes it challenging to allocate further time for projects such as this" (p. 89). The collaborations were fruitful, but they required great effort.

Following the case studies are individual lesson plans. While each lesson plan follows a consistent structure that includes contextual information, learning outcomes, activities, and forms of 
assessment, the descriptions of the activities are often too vague to be useful. There are some exceptions, such as Piotto's lesson plan that includes detailed activities and assessment rubrics; however, most lesson plans do not add new information to their corresponding case study. Additionally, separating the lesson plans and neglecting to state which case studies they connect to creates a sense of disorganization. Yes, the reader can flip around, but it would have been perhaps more effective to put all of the narrative case studies and any supporting lesson plans adjacent especially since most lesson plans are not specific enough to stand alone.

Within the lesson plans, coverage of the framework is uneven. Information Creation as Process and Authority is Constructed and Contextual are referred to often, while other frames receive minimal coverage. Consequently, readers seeking detailed lesson plans or activities regarding ACRL frames may want to stick with other sources like Project Cora or the ACRL Sandbox. Nevertheless, the weaknesses within this section do not detract from the overall value of the book; most case studies provide sufficient detail to inspire new collaborations, and moreover, librarians who are fortunate to work closely with teaching faculty will necessarily develop their own lesson plans that correspond to the unique context of the courses on which they collaborate.

Those interested in assessment will find interesting ideas throughout the book. Each case study describes assessment measures for the information-literacy outcomes of the course. There are traditional means, such as research papers and corresponding rubrics, but as the academic disciplines varied, so do the assessment measures. One interesting project had students revise the syllabus and incorporate at least two ACRL frames into the goals of the course (p. 40). The lesson plans also included assessments, such as write-pair-shares or quizzes. In all, the assessments revealed gains in student success, such as "more focused and varied research by students over the past few semesters" (p. 70). 
Yet, even when noting success, many writers how the frames can truly be assessed within the confines of a single course (pp. 56, 67-68, 73,104,126). Scott Seyve and Stöpel acknowledge, "It might happen that students do very well on research and documenting their research in the co-designed class but do not perform research well or at all in other courses" (p. 56). It seems unlikely that students can master a threshold concept within a semester.

This discussion is not unique; most instruction librarians have questioned how to measure the growth and transfer. What is interesting is seeing that assessment of learning outcomes remains a challenge even under what could be considered ideal circumstances-embedded librarians with multiple points of instruction and full support and partnership from the classroom faculty. If assessment of the framework is slippery even in this context, then what can be done? Writers suggest such solutions as validating co-design experiences in academic departments and committees (p. 55) and creating "ambitious information literacy program across the curriculum" (p. 105).

While any teaching librarian could learn from these models, they would most benefit those with at least some instruction experience. While the cited workshop was geared toward those with little knowledge of the ACRL Framework, the book assumes familiarity on the part of the reader. In addition, librarians likely need to have a rapport with faculty before suggesting such a collaboration, but for those who have established relationships, sharing a case study could be an effective discussion starter. Bigger than a single partnership, the book could serve as an inspiration and foundation for those librarians who would like to create a workshop to educate faculty on the framework and promote collaboration between librarians and faculty across the curriculum, bringing benefit to the teaching partners and their students. In any case, readers should note that any such experiences will require significant time and energy to succeed. 


\section{References}

Association of College and Research Libraries. (2015, February). Framework for information literacy for higher education. http://www.ala.org/acrl/standards/ilframework 